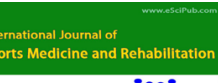

International Journal of Sports Medicine and Rehabilitation $\because-$ (ISSN:2637-5044)

\title{
Physiotherapists and physical activity at work among in Benin and France
}

\section{ALAGNIDE HE, NIAMA NATTA D, AGBO OVE, DJIVOH Y, ASSOGBA F, SOGBOSSI E, DAHOUETO W, KPADONOU GT.}

University Clinic for Physical Medicine and Rehabilitation/ CNHU-HKM (Cotonou/ Benin)

\section{ABSTRACT}

Physical activity at work is an important indicator of the level of activity. Physiotherapists are one of professionals for the prevention against sedentary lifestyle. Objective: To assess the lev${ }^{*}$ Correspondence to Author: ALAGNIDE HE el of physical activity at work among physiotherapists in Benin University Clinic for Physical and France. Method: Descriptive and analytical cross-sectional HU-HKM (Cotonou/Benin) study, conducted from July 2017 to July 2018. With physiotherapists who consent to participate to this study we use a pedometer. They wear it at work for five consecutive days. The average How to cite this article: number of daily steps at work was determined. Physiotherapist's ALAGNIDE HE, NIAMA NATTA D, level of inactivity was assessed using the Baecke questionnaire. AGBO OVE, DJIVOH Y, ASSOGBA Data was analyzed using Epi Info 13.0. X2 of Pearson's and F, SOGBOSSI E, DAHOUETO W, ANOVA tests. They were used for the comparison of qualitative KPADONOU GT. Physiotherapists and quantitative variables respectively. Significance level was and physical activity at work among set at 0.05. Results: Among fifty-four physiotherapists evaluat- in Benin and France. International ed, forty-four (81.5\%) were sedentary, with a significant level of Journal of Sports Medicine and Resedentary lifestyle in twenty-six cases (48.11\%). This limitation habilitation, 2021; 4:15 of physical activity at the workplace and the level of sedentary lifestyle of the subjects were comparable among Beninese and French physiotherapists and they were not associated with any of the factors studied. Conclusion: The level of physical activity of physiotherapists at work is limited. Raising the awareness of Website: https://escipub.com/ these actors seems essential.

Keywords: Physical activity at work, sedentary lifestyle, physiotherapy, Benin, France. 


\section{Introduction}

Physical activity (PA) refers to all the body movements produced by activation of skeletal muscles and causing a substantial increase in energy expenditure above the resting metabolism ${ }^{[1]}$. Benefits associated with regular moderate to intense exercise are well known today ${ }^{[2-5]}$. Physical activity at work is the main determinant of the total level of physical activity ${ }^{[6]}$. There is therefore a need to examine specific relationships between sedentary lifestyle and physical activity at work for different socioprofessional categories, in particular among hospital staff Physiotherapists. The latter are essential players in the fight against sedentary lifestyle and in promoting physical activity (PA) [7-10]. We therefore aimed to assess the level of physical activity of Beninese and French physiotherapists in their professional environment.

\section{Material and methodology}

\subsection{Type and duration of the study}

It was a descriptive and analytical crosssectional study, carried out from July 2017 to July 2018.

\subsection{Study population and sampling}

Population of our study was made up of physiotherapists in activity from two different socio-cultural and economic contexts. These are the south of Benin (departments of Littoral, Atlantic, Ouémé and Plateau) and France (departments of Côte d'or and Haute-Saône).

The sample consisted of physiotherapists working full time in their workplace (study setting), sensitized and having given their consent to participate in the study.

Were excluded, physiotherapists having reported health problems influencing their walking habits.

The main variable in the study was the level of physical activity of physiotherapists in their workplace. It was assessed with the number of steps taken in the workplace. We therefore used "Yamax-SW200" brand pedometer worn on the belt by the physiotherapist and kept continuously during his working hours; this for five (5) consecutive days. Daily record of the number of steps taken was done at the end of the participants' working day, by a student at the end of the Bachelor of Physiotherapy training at the Higher School of Physiotherapy of the Faculty of Health Sciences at Cotonou. To reduce risk of forgetting to wear the pedometer by the participant, a telephone call system has been set up at the start of each working day to remind people to wear the pedometer.

For the categorization of the physical activity level of subjects in their workplace measured from the pedometer, we took into account the international classification for physical activity [11]: $<5000$ steps / day = sedentary, 5000-7499 steps / day = active low, 7500 to 9999 steps / day = rather active, 10,000 to 12,499 steps $/$ day = active, $\geq 12,500$ steps: very active.

To assess the influence of these different factors on the level of PA in the professional environment of our subjects, we redefined the PA classes of our subjects into three main categories: Sedentary, moderately active (grouping together low and low active the fairly active) and the sufficiently active (made up of the active and the very active).

The subjects' level of inactivity was evaluated using the Baecke questionnaire. This questionnaire provides an estimate of the daily physical activity of each physiotherapist. It is a self-administered questionnaire which recalls physical activity over the previous year and has been validated for a general population of both sexes, including different social classes ${ }^{[12]}$.

To define the level of PA according to the Baecke questionnaire, a physical activity index at work (PAI) was calculated from the responses to questions exploring PA at work (questions 6 , $8,9,10,11,12,13$ and 14). For question 6 , it was to assess the type of activity (low, moderate or high) of the patient, taking into account his profession. Note that high activity corresponds to professional athletes, subjects who work in the building industry, etc. (no member of the 
hospital staff has been classified in this category). For question 8 , it was to assess the level of sedentary lifestyle (sitting position) during work, divided into 5 categories ranging from never to always. This level of "nonsedentary lifestyle" consisted in subtracting from 6 the number of points obtained for the question 8. For each question, there are 5 answers which correspond to a number of points which range from very low (1 point) to very high (5 points). The PAI was calculated using the sum of the points in questions $6,8,9,10,11,12,13,14$. Thus, $\mathrm{PAl}=$ work index $=((6-$ points of question
8) + sum of points of the other 7 questions) / 8 . Therefore PAl gives a score between 1 and 5 which allowed us to classify subjects according to 3 levels: low, moderate or important depending on whether their PAI was less than 2.5 , in the range [2.5-3.1] or greater than 3.3 respectively.

Data processing was done by Epi Info version 13.0 software. Pearson's X2 tests and ANOVA were used for the comparison of qualitative and quantitative variables respectively. Significance level was set at 0.05 .

\section{Results}

2.1. Characteristics of the study sample

Table I: Presentation of the characteristics of the study subjects

\begin{tabular}{|c|c|c|c|c|}
\hline & & Beninese & French & Statisticals tests \\
\hline Age (years) & & $\begin{array}{l}33,6 \pm 8,6 \\
\end{array}$ & $35,9 \pm 9,49$ & $F=0,87 ; p=0,35$ \\
\hline \multirow[t]{3}{*}{ Gender } & Male & 11 & 16 & $X^{2}=4,8 ; p=0,03$ \\
\hline & Female & 19 & 8 & \\
\hline & Sex-ratio & 0,58 & 2,00 & \\
\hline BMI $\left(\mathrm{Kg} / \mathrm{m}^{2}\right)$ & & $25,78 \pm 4,87$ & $23,95 \pm 3,24$ & $F=2,49 ; p=0,12$ \\
\hline Professional service (years) & & $9,91 \pm 5,77$ & $11,62 \pm 8,70$ & $F=0,74 ; p=0,39$ \\
\hline \multirow[t]{2}{*}{ Physical activity (PA) practice } & Yes & 9 & 10 & $X^{2}=0,79 ; p=0,37$ \\
\hline & No & 21 & 14 & \\
\hline Duration of PA practice $(\mathrm{min})$ & & $52 \pm 54,54$ & $37,5 \pm 39,50$ & $F=1,19 ; p=0,28$ \\
\hline
\end{tabular}

2.2. Level of Physical Activity

Table II: Physical activity levels of physiotherapists using a pedometer and the Baecke scale

\begin{tabular}{lllll}
\hline \hline & & Beninese & French & Statisticals tests \\
\hline \hline At work (with pedometer) & Sedentatry & 26 & 18 & $\mathrm{X}^{2}=1,2 ; \mathrm{p}=0,27$ \\
& Moderately active & 4 & 6 & \\
With Baecke scale & Important & & & \\
& Moderate & 16 & 10 & $\mathrm{X}^{2}=0,72 ; \mathrm{p}=0,39$ \\
\hline \hline
\end{tabular}


2.3. Factors associated with the level of $P A$

2.3.1. Factors associated with the level of physical activity in workplace

Table III: Presentation of factors associated with the level of physical activity of physiotherapists in workplace.

\begin{tabular}{lllll}
\hline \hline & & Sedentary & Moderately active & Statisticals tests \\
\hline \hline Age (years) & Mean \pm SD & $34,5 \pm 9,34$ & $35,2 \pm 7,94$ & $\mathrm{~F}=0,04 ; \mathrm{p}=0,82$ \\
Gender & Male & 23 & 4 & $\mathrm{X}^{2}=0,49 ; \mathrm{p}=0,48$ \\
& Female & 21 & 6 & \\
$\begin{array}{l}\text { Duration of service } \\
\text { (years) }\end{array}$ & Mean \pm SD & 10,36 & 12,05 & $\mathrm{~F}=0,44 ; \mathrm{p}=0,51$ \\
BMI & Mean \pm SD & $24,81 \pm 4,16$ & $25,64 \pm 4,99$ & $\mathrm{~F}=0,30 ; \mathrm{p}=0,58$ \\
PA practice & Yes & 27 & 8 & $\mathrm{X}^{2}=1,24 ; \mathrm{p}=0,26$ \\
& No & 17 & 2 & \\
Duration of PA & Mean \pm SD & $46,36 \pm 50,59$ & $42 \pm 40,49$ & $\mathrm{~F}=0,06 ; \mathrm{p}=0,80$ \\
\hline \hline
\end{tabular}

2.3.2. Factors associated with the level of PA according to Baecke scale

Table IV: Presentation of factors associated with the level of physical activity of physiotherapists according to Baecke scale.

\begin{tabular}{lllll}
\hline \hline & & Important & Moderate & Statisticals tests \\
\hline Age (years) & Mean \pm SD & $33,65 \pm 8,56$ & $35,53 \pm 9,51$ & $\mathrm{~F}=0,58 ; \mathrm{p}=0,44$ \\
Gender & Male & 13 & 14 & $\mathrm{X}^{2}=0,00 ; \mathrm{p}=1$ \\
& Female & 13 & 14 & \\
Duration of service (years) & Mean \pm SD & $10,38 \pm 7,2$ & $10,94 \pm 7,3$ & $\mathrm{~F}=0,08 ; \mathrm{p}=0,77$ \\
& & & & \\
BMI & Mean \pm SD & $25,23 \pm 5,32$ & $24,72 \pm 3,12$ & $\mathrm{~F}=0,18 ; \mathrm{P}=0,66$ \\
PA practice & Yes & 18 & 17 & $\mathrm{X}^{2}=0,42 ; \mathrm{p}=0,51$ \\
& No & 8 & 11 & \\
Duration of PA & Mean $\pm S D$ & $39,03 \pm 37,94$ & $51,60 \pm 56,71$ & $\mathrm{~F}=0,90 ; \mathrm{p}=0,34$ \\
\hline \hline
\end{tabular}

\section{Discussion}

\subsection{Characteristics of the study sample}

According to Table I, in addition to sex $(p=0.03)$, physiotherapists in the two groups are comparable according to the characteristics studied. They were especially young adults, normal corpulence, in professional activity for about a decade. Only about one in three physiotherapists practiced sports activities outside of service work time. These results could be explained by the fact that physiotherapists find the practice of their profession already quite physical and therefore no longer requires additional activities.

\subsection{Level of physical activity}

None of the subjects in the study had a satisfactory level of physical activity at the workplace, whether they were Beninese or French. Work carried out in other socio-cultural contexts and among other health professionals 
has led to the same conclusion, with average daily steps of $2323^{[13]}$. The recall of the level of physical activity according to Baecke questionnaire also confirms this limitation in the level of physical activity of the subjects of the study.

\subsection{Factors associated with the level of physical activity}

None of the different factors studied were significantly associated with the level of physical activity of the study's subjects. But Suija et al. showed in 2010 that there is no significant correlation between age and level of physical activity among doctors in Estonia [14]. In South Africa ${ }^{[15]}$ and Nigeria ${ }^{[16]}$, other authors have concluded that the older the patient is, the least is his level of physical activity.

Our results were consistent with those reported in South Africa, showing that there is no significant association between gender and the level of physical activity among health professionals ${ }^{[15]}$. Oyeyemi et al in a study from Nigeria also found that there is no significant difference between men and women about their level of physical activity [16]. This observation was, however, contrary to certain socio-cultural prejudices according to which women have a lower physical condition than men.

\section{Conclusion}

The majority of physiotherapists are sedentary in both France and Benin. Those who are moderately active do not meet $\mathrm{WHO}$ international recommendations for physical activity. Socio-professional factors and lifestyle varying from one culture to another did not influence the level of physical activity of our subjects in both populations.

Additional studies will have to be carried out in order to confirm our results but also and above all to assess the overall PA of physiotherapists and other health professionals.

\section{Conflict of interest : None}

\section{References}

[1]. Caspersen CJ, Powell KE, \& Christenson GM. Physical activity, exercise, and physical fitness: definitions and distinctions for health-related research. Public Health Reports 1985; 100(2): 126-31.

[2]. Corbin, Charles B, Pangrazi, Robert P, Franks B. Don. Definitions: Health, Fitness, and Physical Activity. Physical Fitness and Sports Research Digest 2000; 3: 9.

[3]. Nelson ME, Rejeski WJ, Blair SN, Duncan PW, Judge JO, King AC et al. Physical activity and public health in older adults: recommendation from the American College of Sports Medicine and the American Heart Association. Medicine and science in sports and exercise 2007; 39(8):1423-45.

[4]. Le Masurier GC, Sidman CL, Corbin CB. Accumulating 10,000 steps: does this meet current physical activity guidelines? Research Quarterly for Exercise and Sport 2003; 74(4):389-94.

[5]. Pate RR, O'Neill JR, Lobelo F. The evolving definition of "sedentary". Exercise and Sport Sciences Reviews 2008; 36(4):173-8.

[6]. Omorou AY, Coste J, Escalon H, Vuillemin A. Patterns of physical activity and sedentary behaviour in the general population in France: cluster analysis with personal and socioeconomic correlates. Journal of Public Health 2016; 38(3):483-49.

[7]. Katz MP, Church TS, Craig CL, Bouchard C. Sitting time and mortality from all causes, cardiovascular disease, and cancer. Medicine and science in sports and exercise 2009, 41: 998-1005.

[8]. Verhagen E, Engbers L. The physical therapist's role in physical activity promotion. British Journal of Sports Medicine 2008; 43(2):99-101

[9]. Hart DL, Isernhagen SJ, Matheson LN. Guidelines for functional capacity evaluation of people with medical conditions. Journal of Orthopaedic \& Sports Physical Therapy 1993; 18 (6): 682-6.

[10]. Brewer W, Ogbazi R, Ohl D, Daniels J, Ortiz A. A compararison of work-related physical activity levels between inpatient and outpatient physical therapist : an observational cohort trial. BMC Research Notes 2016; 9: 313

[11]. Tudor-Locke C, Hatano Y, Pangrazi RP, Kang M. Revisiting "How Many Steps Are Enough?"Med. Sci. SportsExerc 2008; 40(7) : 537-43.

[12]. Baecke JAH, Burema J, Frijters JER. A short questionnaire for the measurement of habitual physical activity in epidemiological studies. Am J Clin Nutr. $1982 ; 36:$ 936-942.

[13]. Conzett-Baumann K, Jaggi GP, Hüsler $A$, Huesler J, Beer $\mathrm{JH}$. The daily walking distance of young doctors and their body mass index. 
European Journal of Internal Medicine $2009 ; 20(6): 622-4$.

[14]. Suija K, Pechter U, Maaroos J, Kalda R, Rätsep A, Oona M, Maaroos H-I. 'Physical activity of Estonian family doctors and their counselling for a healthy lifestyle: A cross- sectional study', BMC Family Practice $2010 ; 11: 48$.

[15]. Kunene SH, Taukobong NP. Level of physical activity of health professionals in a district hospital in KwaZulu-Natal, South Africa, South African Journal of Physiotherapy $2015 ; 71(1)$ :234-6

[16]. Oyeyemi A, Jidda Z, Baagana F. Prevalence of physical activity among adults in a metropolitan Nigerian city: A cross- sectional study', Journal of Epidemiology.2013; 23(3) : 169-77. 